\title{
Cronotopía del Caribe: Una mirada a la Poética de la Casa caribeña
}

\author{
Caribbean Chronotopy: A Look at the Poetics of the Caribbean House
}

\section{Cronotopia do Caribe: Um olhar sobre a poética da Casa do Caribe}

\author{
Angélica María Sierra Franco \\ Arquitecta, Especialista en Gerencia Ambiental y Gestión de Procesos \\ Urbanos Sustentables de la Corporación Universitaria del Caribe-CECAR. \\ MSc (c) en Hábitat. Universidad Nacional de Colombia. \\ angelica.sierraf@cecar.edu.co \\ iD https://orcid.org/0000-0003-2095-2028
}

Recibido: abril 1 de 2020

Aceptado: mayo 29 de 2020

Publicado: junio 4 de 2020

\section{RESUMEN}

A partir de una construcción semántica de la experiencia del habitar, se reflexiona sobre la intertextualidad referida a la mirada cronotópica de la Casa caribeña, en la importancia cultural de la formación de lugares y su relación estética como imagen en la Literatura colombiana. La Casa caribeña es un dispositivo geo-simbólico, que trasciende los valores físico-espaciales, y denota su carácter antropológico y social representando la corporeización de una determinada cultura, que se verbaliza a través del imaginario colectivo, en una Literatura necesaria para captar y exteriorizar la fuerza de un espacio-tiempo geográfico y cultural.

Palabra clave: Hábitat, Cronotopo, Cultura, Casa, Identidad, Literatura

\section{ABSTRACT}

Starting from a semantic construction of the experience of living, the intertextuality referred to the chronotopic view of the Caribbean house is reflected on the cultural importance of the formation of places and their aesthetic relationship as an image in Colombian literature. The Caribbean house is a geo-symbolic device, which transcends physical-spatial values, and denotes its anthropological and social character, representing the embodiment of a certain culture, which is verbalized through the collective imagination, in a literature necessary to capture and externalize the strength of a geographic and cultural space-time.

Keyword: Habitat, Chronotope, Culture, Home, Identity, Literature

\section{RESUMO}

A partir de uma construção semântica da experiência de habitar, pondera reflete sobre na intertextualidade referida ao olhar cronotópico da Casa caribenha, na importância cultural da formação de lugares e sua relação estética como imagem na Literatura colombiana. A Casa caribenha é um dispositivo geo-simbólico, que transcende valores físico-espaciais e denota seu caráter antropológico e social, representando a personificação de uma certa cultura, verbalizada através da imaginação coletiva, em uma Literatura necessária para capturar e exteriorizar a força de um espaço-tempo geográfico e cultural.

Palavras-chave: Cronotopo, Cultura, Lar, Identidade, Literatura, Habitat 


\section{INTRODUCCIÓN}

La Casa, en su contexto antropológico, se define como un espacio personal que demarca límites simbólicos plasmados en sus formas, espacios y materiales; representando, a la vez, un microuniverso íntimo y familiar, creado y recreado libremente con criterios prácticos, estéticos y expresivos, transversalizados por el arraigo, las formas de vida y la construcción colectiva de una identidad cultural, que el habitante trae a cuestas en su cronología vital y que se materializa como una estética social, figurativa y orgánica, expandida en el sentido de la disposición y ordenación del espacio y en la manera como se percibe y se hace propio.

Este universo simbólico de la Casa, es, a su vez, una expresión de la influencia que ejerce una región geográfica y cultural sobre las formas en que se explora y se construye la realidad humana, derivada en estructuras de redes colectivas que configuran espacios y los habitan. El desarrollo de estos acontecimientos, en el acto de habitar, refrenda, en la memoria del habitante, como un marco de representación, vínculo simbólico y significante entre los espacios y las personas, analizado desde múltiples perspectivas bajo los conceptos de apropiación, arraigo, apego al lugar, identidad (Vidal y Pol, 2005).

La reflexión que se suscita en este artículo se centra en las categorías de la Casa y el Cronotopo, siendo este último dos categorías en sí mismo, tiempo y espacio, que se conjugan desde dos perspectivas dialógicas, el acto de habitar los lugares, en una especie de sociología del espacio (organización espacial y experiencia humana), y la construcción de imágenes lingüísticas en la Literatura; ambos elementos revelan el valor identitario que permanece en la memoria colectiva, subjetiva y objetiva, de una región y que le otorga particularidades que la extienden a las trazas de la globalidad.

El objetivo es reconocer la existencia de una identidad arquitectónica regional, que se particulariza en las formas de configurar las estructuras espaciales en las cuales las acciones encuentran su propio sentido y que se manifiestan en las materializaciones de la Arquitectura y la Literatura como lenguajes dialógicos de la condición humana (Ricoeur y Muntañola, 2002).
La lectura de este hilo conductor demarca, en primera instancia, la contextualización del tejido del sistema territorial en el que se configuran las ciudades y las Arquitecturas del Caribe colombiano y que se constituye en una imagen geo-estética presente en las demarcaciones psicosociales de los modos de vida de los habitantes de las mismas. Esto permite explorar mediante los correlatos de los espacios, la formación de lugares cronotópicos en la Casa caribeña. Lugares que, por la experiencia humana (acción: tiempo y espacio), articulan el proyecto con el habitar y son considerados semánticamente como espacios simbólicos, con alta carga significativa, "cuya articulación es cultural y socialmente motivada" (Muntañola y Muntañola, 2010, p. 137).

Estos correlatos, se ponen de manifiesto en la Literatura del Caribe colombiano, a través de autores que, en sus obras de prosa y poesía, dejan entrever con efectividad artística, matices regionales de una realidad cultural y espacial, que se constituye, a su vez, en una "representación del universo vital autobiográfico" (Valdelamar, 2008). Por lo que se hace necesario establecer un dialogo entre las construcciones literarias que dejan evidencia de la imagen cronotópica de la Casa y elementos de la sociologia del espacio, presentes en los discrusos de Paul Ricoeur (2002), Josep Muntañola (2010) y otros exponentes de la experiencia social de la Arquitectura y su construcción de una identidad cultural-territorial.

\section{METODOLOGÍA}

El presente artículo pretende profundizar en un aspecto específico de la investigación "Transición Cultural de Hábitat: de la Casa Comunitaria a la Vivienda Estándar", que concierne a la dialógica intertextualidad entre las representaciones del universo vital y el universo narrativo, como recurso simbólico y expresión espacio-temporal de la experiencia social del dispositivo de la Casa, en el contexto regional caribeño. Sin la expresión figurativa en el signo, en este estudio -la palabra-, el pensamiento abstracto/subjetivo del hombre no puede conservarse en la memoria colectiva, sino, únicamente, en las formas objetivas de la cultura misma en las que se recrean la Arquitectura y la Literatura. 
Para llegar a ello, se realizó una revisión documental que esboza la relación, en la categoría del Cronotopo, tanto a la imagen literaria del Caribe colombiano como a la imagen espacial de la Casa caribeña, con el fin de identificar la formación semántica de los lugares que representan una huella en la memoria colectiva regional. De este modo, el espacio y el tiempo, medido a través de la significación de la experiencia humana en sus usos, rituales y prácticas del habitar, representan una unidad indisoluble como estructura cronotópica esencial, asimiladas artísticamente en la Literatura (Valdelamar, 2008).

Las fuentes se obtuvieron de bases de datos especializadas en Ciencias Sociales, especialmente en Arquitectura, Sociología, Geografía y revisiones de obras literarias de escritores del Caribe colombiano, de prosa y poesía, como Gabriel García Márquez (2007), Héctor Rojas Herazo (1986), Beatriz Vanegas Athías (2006), Raúl Gómez Jattin (1995), entre otros. Esto permitió hacer una clasificación en donde se evidencia el uso del Cronotopo de la Casa en alguna de sus configuraciones espaciales, por lo que se concretaron los espacios del patio, la cocina, la puerta/terraza y la calle, como elemento recurrentes y permanentes en el universo vital del habitante caribeño.

La reflexión suscitada, gira en torno a la siguiente hipótesis: la estructura cronotópica de la Casa caribeña -como dispositivo geo-simbólico de los elementos de identidad cultural- dialoga semánticamente en la imagen estética de la tradición literaria del Caribe colombiano. Así, la Casa en el Caribe representa la materialización de los elementos de identidad del habitante, su estructura geográfica de soporte y sus formas de vivir; este elemento trasciende los valores físicoespaciales y denota su carácter antropológico y social, quedando latente en las formas lingüísticas verbales y no verbales de la Literatura.

\section{SENTIDOYSIGNIFICADODELCRONOTOPO}

El Cronotopo es un concepto de asimilación literaria, desarrollado por Bajtin en 1989, con el cual representa las unidades compuestas de espacio (marco geográfico) y tiempo (marco histórico) en la configuración de la narrativa literaria, sobre los cuales se recrea la acción del personaje. Este concepto se extiende, posteriormente, a los estudios de las Artes en general, transversalizado por las
Ciencias Sociales, el cual explica, insistentemente, que la construcción de la experiencia espaciotemporal humana es producto de una construcción social y cultural (Muntañola y Muntañola, 2010).

Para acometer el trabajo de interpretación del territorio habitado, en la unidad bio-tecnotópica de la Casa y sus dinámicas espacio-temporales estructuradoras, apelamos a este concepto en su doble connotación, como metáfora y como noción, y que adoptamos en su doble acepción por su capacidad potencial de incursionar en los aspectos estéticos de las etnias locales y su papel configurador de estilos asociados a lo corpóreo, lo afectivo, lo ancestral, las relaciones sociales, la familia, el medio natural, etc.

Estas figuras espacio-tiempo dan nuevos sentidos y significados cuando se conectan al concepto del Cronotopo, pues con este la Literatura y las narrativas de los saberes y las ciencias del hombre comprenden, interpretan y definen formas de tiempo que se vuelven visibles, apreciables y sensibles a la experiencia humana, conexiones de las relaciones temporales y espaciales, en donde la forma, por acción del tiempo, cobra vida y dimensión en el significado histórico real del habitante (Bajtin, 1989).

El tiempo se condensa aquí, se comprime, se convierte en visible desde el punto de vista artístico; y el espacio, a su vez, se intensifica, penetra en el movimiento del tiempo, del argumento, de la historia. Los elementos del tiempo se revelan en el espacio, y el espacio es entendido y medido a través del tiempo. La intersección de las series y uniones de esos elementos constituye la característica del Cronotopo artístico (Bajtín, 1989, p. 238).

El tiempo se materializa en el espacio, dando origen a formas de la realidad más auténticas, en donde el hombre construye su imagen a partir de dos elementos, sus percepciones y representaciones elementales, con las cuales se da sentido a las informaciones procedentes del exterior y constituyen el legítimo proceso de conocimiento y valoración, tal como lo describe Kant (1787) en su texto Critica de la razón pura.

Lo que nos indica que el Cronotopo es la estructura de representación del paso del hombre en el espacio, como sujeto físico de la acción; un hombre vivo, con identidad en sí mismo, capaz de darle significación y profundidad ideológica a la identidad 
humana (Bajtín, 1989), dando cuenta de los signos que quedan inteligiblemente incorporados en la conformación de los lugares en donde el hombre genera la acción y la significación, como códigos expresados en los encuentros, las separaciones, las búsquedas, los motivos y los acontecimientos, es decir, en el momento emotivo-valorativo que se impregna en la espacio-temporalidad.

Este mismo autor categoriza el valor del Cronotopo para la Literatura, según el nivel de la intensidad emotiva-valorativa en la conformación de una identidad cultural narrativa, es decir, que a mayor intensidad más sensible es al ser humano el signo (para este caso, la palabra y el proyecto), adquiriendo mayor nivel afectivo; por tanto, mayor es la pregnancia de la estructura espacio-temporal (sistema de lugares) en la mente del hombre, en sus estados de memoria y en sus expectativas, como vestigios de la trayectoria del tiempo.

El Cronotopo en el estudio de la Arquitectura y los modos de habitar como "actos culturales en los que se integran las respuestas materiales con las concepciones acerca del mundo, del sentido de la vida y del sentido mismo de habitar" (Saldarriaga, 2019), se hace evidente cuando se logra una comprensión profunda del "carácter y significado social del espacio" (Ricoeur, 2002), el cual le atribuye, por defecto, un carácter simbólico a la experiencia humana que hace que los espacios, por la vivencia (espacio-temporal) de los habitantes, adquieran significación afectiva y representación en los niveles de la cotidianidad y la memoria. Esta interpretación, convierte a los espacios en lugares de alta carga subjetiva, con gramáticas objetivas de sociabilidad y repertorios de prácticas culturales colectivas; las formas de tiempo sirven como dinámica configuradora de la construcción de las identidades sociales, en donde el tiempo adquiere un carácter concreto-sensitivo y los lugares se llenan de vida, posibilitando la representación y expresión del mundo.

\section{RASGOS DE IDENTIDAD CARIBE}

Hablar de la identidad cultural de la región del Caribe, es adentrarse a un amplio, complejo y particular segmento del mundo al que pertenece la porción norte de la Costa colombiana en América Latina. Esta característica geográfica representa el mapa físico y cultural de la dimensión humana del habitante Caribe y le permite reconocer una diversidad integrativa que lo conecta con todos los hemisferios.
Así, el ser humano, en la necesidad de encontrar sus raíces, incursiona en la búsqueda de su identidad, como elemento clave para revelar los elementos incidentes en su proceso de reconocimiento individual y colectivo, que le puede significar pertenecer a este territorio. Tal como lo afirma Gustavo Bell Lemus (1999) "estas inquietudes parecen ser naturales a todos los pueblos y parecen estar inmersas en el deseo de la gente de organizar y codificar su experiencia pasada y colectiva, al mismo tiempo que echar las bases de sus futuras aspiraciones" (p. 3).

Sin embargo, la construcción de identidad es un transcurrir cultural, material y social, por lo que referirse al Caribe, en palabras de Jorge Nieves Oviedo (1999), es hablar de "procesos, gentes, pensamientos, sensaciones, cifras, pobreza, marginación, cuerpos, sabores, tumbaos y mucho más" (p. 21); definiéndose el ser humano a sí mismo en términos de categorías compartidas, en la proyección simbólica de su percepción del mundo y en la identificación de los "otros" dentro de su propio universo, y cuyos intereses se internalizan bajo la consigna del "nosotros"; sin embargo, delimitar esto en territorios del Caribe resulta complejo. Al respecto de este tema, Nieves Oviedo (1999) afirma, que:

Aunque no podemos elaborar sobre lo Caribe una definición con valor taxonómico indiscutible, todos experimentamos la caribeñidad y sabemos qué es, pero lo sabemos con el conocimiento silencioso, ese que se elabora con toda nuestra percepción desde nuestro otro, desde el lado sensible de nuestra naturaleza (p. 23).

La geografía del Caribe se define por la cuenca del mar Caribe, que comprende una cartografía arquetípica constituida por un conglomerado de islas y territorios continentales circunmarítimos, con una entidad espacial propia de un paisaje tropical que no sólo unifica a América, sino que lo convierte en los brazos extendidos hacia el resto de los continentes (Camargo, 1994).

Las poblaciones que se asientan en estos territorios, representan una combinación de razas y culturas, producto de su heterogénea herencia de poblamiento, que hacen del Caribe una región cuya identidad radica en la diversidad, tanto del entorno físico y geográfico, como de las tradiciones, formas lingüísticas, expresiones artísticas y temperamentos de sus habitantes (Díaz, 2014, p. 7). 
Esta determinación geográfica incide en la generación de oportunidades comunicativas que activan las relaciones sociales interculturales e intraculturales, es decir, el Caribe se convierte en una invitación al intercambio con los de "afuera" y a la cohesión con los de "adentro", producto del ambiente creador del contexto natural y su influjo sobre el espíritu caribeño. Determinación que adquiere sentido ante los estudios concernientes de la geografía humana y la psicogeografía, cuya propuesta radica en comprender los efectos de los ambientes geográficos como representaciones simbólicas, sobre el comportamiento y las emociones humanas (Ellard, 2016), por lo que la contextualización del Caribe, adquiere una significativa importancia cuando se reconoce que las diferenciaciones y sinergias del pensamiento y sentimiento del habitante Caribe se enraízan en lo que este ve y percibe.

Poco hemos analizado el carácter de ser moradores de una geografía donde se viene a recalar el mar, las montañas, las islas y los vientos, lo que nos infunde una naturaleza abierta a todos los horizontes. Ser caribeños nos hace herederos de la sangre de los aborígenes más aguerridos, cuya belicosidad les dio el predominio sobre todas las etnias del litoral. Esto quiere decir que desde el más remoto ancestro fuimos y continuamos siendo mestizos. No hay, pues en Colombia, hombre, hábitat, filosofía, comportamiento, tecnología que no encuentre en el caribeño su más antigua raíz (Zapata citado por Contreras, 2006).

Pensarse como habitante de este territorio, afirma Nieves Oviedo (1999), es "registrarse dentro de una existencia primero Caribe y después nacional" ( $p$. 24), lo que determina una jerarquización del sentido de pertenencia y la construcción de una identidad regional en el marco del imaginario Caribe. El elemento humano de esta porción del territorio debe entenderse a partir de los tres troncos étnicos presentes en él: el africano, el blanco y el indio, los cuales "no fueron asimilados desde un principio y no realizaron una cabal integración, sino, en las proporciones que limitaron los alzamientos de estos grupos. El sistema de rochelas los mantuvo en núcleos defensivos hasta hace poco tiempo" (Gutiérrez, 1996, p. 65), asunto que conlleva a una intensificada cohesión social étnica y la categorización del Caribe como una unidad diversa.
El caribeño parece ser extrovertido, pero en su más profundo sentimiento es tímido, por su legado de indio. Refleja ser pagano y pachanguero, pero es muy religioso frente a sus muertos. Tiene fama de echador de cuentos, pero no es más que el antioqueño con el cual tiene en común el abuelo negro. Mal hablados, pero puristas cuando queremos expresarnos bien. Religiosos, pero no beatos. Constantes en el ser, inconstantes en el hacer. Valientes para vivir y cobardes para morir (Zapata, 2006, p. 13).

Esta diversidad cultural forjó en el habitante Caribe dos características fundamentales; en primer lugar, un fuerte arraigo por el legado indígena, evidenciado a través de las tradiciones culturales y materiales que se mantienen presentes en los rituales festivos, la interrelaciones y la preferencias arquitectónicas; en segundo lugar, una apertura y permeabilidad hacia los "otros", en donde el habitante se mantiene abierto a las expresiones foráneas, las cuales asimila y adapta a sus intereses, de manera que busca siempre una hibridación que mantiene lo aborigen y lo externo dentro de un mismo tejido (Camargo, 1994).

\section{CRONOTOPÍAS: LUGARES DE IDENTIDAD EN EL CARIBE COLOMBIANO}

La conformación de los lugares de identidad en la Casa caribeña, está representada en el significado que sus habitantes les otorgan a los espacios que habitan, como memorias de sus prácticas y rituales cotidianos y huella de las espacialidades cargadas simbólicamente en los objetos de representación.

Estos lugares constituyen cargas afectivas en la memoria colectiva de los caribeños y se convierten en los lugares de añoranza y expectativa; así, el caribeño los lleva a donde quiera que va, replegando su evocación en las evoluciones de la Casa, de ahí que en las viviendas modernas, apartamentos de edificios, viviendas de interés social, entre otras manifestaciones tipológicas emergentes de la vivienda, aparezcan, de alguna manera, pequeñas huellas simbólico-espaciales; los balcones se convierten en patios frondosos de aromáticas que a lo lejos permite ver el transcurrir dinámico de la calle. 
La intertextualidad se hace consecuente en la Literatura que, como recurso de expresión, permite concentrar y perpetuar la carga socio-afectiva de una región que tiene una identidad cultural marcada a través de su realidad espacio-temporal. Las figuraciones literarias anudan los elementos geográficos, con los rasgos históricos y culturales de la realidad existencial del Caribe colombiano, "para dibujar sobre la espejeante superficie del Caribe, un rostro, una representación, una lectura del hombre y de una geografía" (Bustos, 1999).

\section{EL PATIO}

La Casa caribeña, guarda un pedazo de naturaleza en el interior de objeto construido, un lugar que nace de la necesidad de vincular las experiencias de la ruralidad ancestral en un dispositivo materialmente urbanizador. Este espacio aparece en la Casa del Caribe como un lugar, poseedor de unas características ambientales que configuran un microclima que hace más soportables las indulgentes variaciones climáticas de la zona de vida tropical; también concentra las imágenes vivenciales del transcurso de la vida caribeña, sucedida más afuera que adentro de las casas, acción que ejerce una fuerza en las representaciones individuales y colectivas de la cotidianidad, que se significan y se construyen como un legado de la memoria.

Este caso es evidenciado en la obra de Rojas Herázo (1986), titulada Celia se pudre, con la que este importante autor de la Literatura caribeña, expresa el simbolismo del Cronotopo del patio en múltiples sentidos, que van desde "lo meramente geográfico hasta lo más intimista y humanizante" (Pineda citado por Valdelamar, 2008).

Estás viendo tu patio, Celia. / Sí, lo sigo viendo porque lo he mirado y remirado mucho. (...) / ¿Qué sientes, niña mía, cuando ves estos rincones? / Como si algún día me fueran a castigar sacándome de aquí. Sería el único castigo, ningún otro lo sentiría como ese. Que me arranquen de aquí donde tengo mis muertos. Donde mis muertos caminan por mi sangre al caminar por mi patio, donde se han podrido mis flores. ¿Has olido mi patio? Nadie puede olerlo como yo. Cada vez que lo hago vuelven mis mañanas y mis noches y mis hijos muertos me miran y, siguen aquí, sentados conmigo en el comedor. Tú no sabes lo que es un árbol cuando las ramas tienen el color de los ojos de tus hijos. No lo sabes. Como tampoco sabes lo que llega en el crepúsculo cuando limpias el tubo de una lámpara, mirando el patio en que has envejecido. $\mathrm{O}$ lo que pasa en la brisa cuando le salen florecitas al naranjo. No, no lo sabes. (Rojas, 1986, p. 467)

En este lugar, generalmente sembrado de árboles y plantas de ornamento, aparece la temporalidad de la infancia con sus rituales de juegos y demás prácticas de interacción familiar, descritas en el poema de Gómez Jattin (1995) titulado "Que te vas a acordar de mí Isabel" que recita lo siguiente: "Qué te vas a acordar Isabel / de la rayuela bajo el mamoncillo de tu patio / de las muñecas de trapo que eran nuestros hijos (...)" (p. 23), al mismo tiempo, aparecen otras temporalidades, como la vejez, descrita en el texto de Rojas Herázo (1985), en el que la memoria del patio adquiere significados adjudicados a los recuerdos; esta temporalidad trae a presente otras temporalidades que se yuxtaponen y le otorgan una alta carga simbólica y un importante valor identificatorio.

Por esta razón, para el caribeño, un requisito esencial que debe llevar la vivienda es la existencia de un patio (Valdelamar, 2008), en él se entrenan los sentidos, donde el hombre se pone de pie ante el solar y ante el mundo. La confluencia de los sonidos de la naturaleza, los olores atraídos por el viento y las sensaciones de la tierra en nuestra piel, se conectan con los rituales cotidianos que en este espacio ocurren "El Caribe es el gran patio, en donde está la estructura de toda una cultura, de una civilización, de una forma, de un color y de un idioma" (Rojas H. , 2006).

Los tiempos de permanencia en el patio caribeño son prolongados; en él se desarrollan la mayor parte de las actividades cotidianas de la Casa, sean o no su lugar más funcional; esto, gracias al microclima generado por el espacio abierto entre los árboles y la cercanía al punto de agua. Por tanto, es el lugar de reunión de visitas familiares y conocidos más cercanos, el lugar del juego, de las labores de mayor estancia e incluso actividades de la cocina son llevadas a cabo muchas veces en el patio. Asunto que permite que se entretejan las vivencias y se signifiquen con recuerdos que en la mente humana imprimen sobre este lugar gran parte de la afectividad toponímica, convirtiendo al patio en el Cronotopo caribeño de mayor importancia. 
Un patio no es un jardín como los de las casas de otras latitudes. Los jardines de nuestras casas están, por lo general, en la entrada y son pequeños. Los patios son inmensos y están detrás. Son el universo infinito en el que caben trastos viejos, la troja para lavar los platos, las cuerdas donde se seca la ropa y el corral de las gallinas. En el Caribe colombiano, la vida no transcurre dentro de las casas, sino fuera: en el frente donde vuelan los chismes y las peleas, y en el patio donde vuelan los sueños y las frustraciones (Moreno, 2020).

La importancia cultural del patio de las casas en el Caribe colombiano, proviene de la interacción con el contexto natural de los indígenas y la tradición histórica de los patios españoles. El patio pasó de ser un sitio geográfico, para cobrar importancia como espacio antropológico y social, significativo para el desarrollo de la vida cotidiana, es una porción de la naturaleza dentro de la Casa, una prolongación del paisaje (Martínez, 2013).

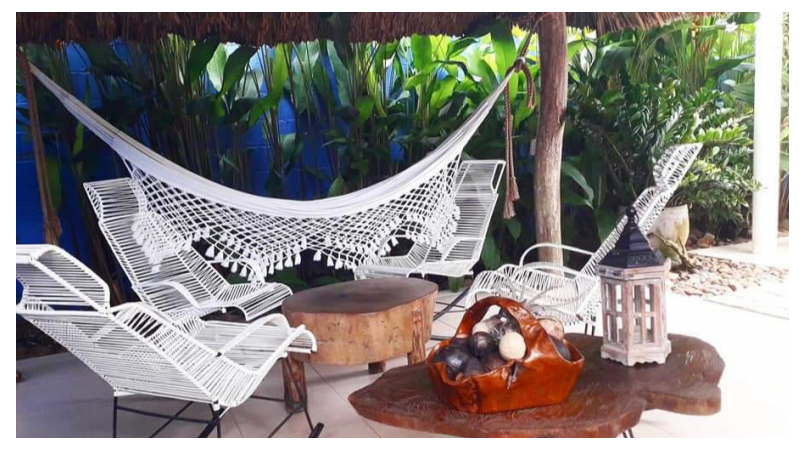

Figura 1. Patio caribeño en casa tradicional. Mezcla de elementos naturales y artificiales, mobiliarios tradicional de la región Caribe.

Fuente: la autora.

\section{LA PUERTA}

La puerta constituye el límite entre el mundo ajeno y el mundo familiar. Un estrechamiento del espacio, una aproximación de territorios, el "aquí" y el "en otra parte"; por lo que la puerta es un dispositivo que separa, pero que, a la vez, unifica. Los mundos que se sitúan a un lado y otro del umbral, se ubican en el contexto de lo ideal y lo material a la vez y se presentan como un elemento fundamental de una topología social que constituye el universo de los rituales espaciales erigidos en la cotidianidad del habitar, hecho que le otorga un carácter cronotópico a este lugar. Estos mundos son expresados por la poeta Beatriz Vanegas Athías (2006), en su poema
Las puertas, del libro Lugares comunes:

Cuando abres la puerta de tu casa (...)

(...) Hallarás la alegría en la carta que te anuncia el fin de la ausencia.

La desazón y las sin salidas en los recibos incalculables.

El aburrimiento en la visita indeseada.

La ilusión en la invitación anhelada.

La zozobra en los golpes a la medianoche.

Abres la puerta para salir de la jaula.

Cierras la puerta para proteger el amor y desbordar la ternura.

Al pie de la puerta añoras a quien se fue.

Al pie de la puerta ocurre el regreso.

La tarde entra por ella y el alba y su soledad también. (Vanegas, 2006)

La puerta es el lugar donde se transponen los límites del territorio privado y el territorio público, para encontrar al otro en el comienzo de su propio territorio, con el fin de que se lleve a cabo el intercambio. Este elemento, que se presenta como el dispositivo material del umbral, tiene consigo el traspaso, como rito accionante y que resulta evidente en la narrativa poética de Vanegas Athías, al contextualizar como un Cronotopo literario la experiencia cotidiana del ser humano en esta espacio-temporalidad.

El umbral funda los espacios y existe desde que se ha tenido intensión de separar un lugar del resto del mundo: el adentro, es un espacio finito y cerrado de cualidades íntimas, elegidas y controladas, en el que se construye la identidad personal y familiar; el afuera, es el espacio infinito, abierto y común en el que se construyen las redes sociales y se ponen en consideración las instancias de lo público, como dimensiones del habitar en el espacio social. La puerta se abre para la entrada, y esto trae la carga simbólica de la interioridad y el encuentro con uno mismo. La puerta se abre para la salida, para el encuentro con el otro, el intercambio y la socialización.

En la Casa del Caribe el dispositivo de la puerta se encuentra generalmente abierta, aunque esto no necesariamente signifique el traspaso libertino del umbral; sin embargo, su franqueo no está restringido. Estar a un lado o al otro de la puerta le da la posibilidad al habitante de pertenecer al ambiente de lo público o de lo privado. Estar afuera, sentados al exterior de la puerta principal de la Casa, es tener los ojos bien abiertos y la disposición 
para el tratamiento de los temas colectivos, de entablar las relaciones con el caminante y de abrir la mente a lo acontecido en la cotidianidad del mundo exterior. Estar adentro, con la puerta cerrada, significa estar en el lugar de lo íntimo donde se resuelven los temas familiares y se llevan a cabo las actividades que no necesariamente deben ser expuestas al público curioso de la calle. Estar adentro, con la puerta abierta, es dejar la vía libre para la penetración al habitáculo, para el intercambio en el territorio propio.

La connotación cronotópica de la puerta como dispositivo fundador de lugares en la Casa de caribe, aparece acompañado obligatoriamente, de los espacios de la terraza y la calle, como soportes de la dinámica vivencial del habitar. Esto se refleja en la Literatura de Gómez Jattin, cuando señala, a través de su poesía, los correlatos que suceden en este paisaje íntimo de lo público, como un elemento de reafirmación de la identidad cultural caribeña en sus ámbitos de efusiva exterioridad.
Dentro de este paisaje emerge el hombre caribe imbuido en su cotidianidad de héroe: La abuela que oye novelones de radio desde la calle y discute con los malos; las comadres aceitosas que parlotean y se mecen en las puertas de las terrazas hasta que muere el sol. (Ferrer, 2002).

Por otra parte, En la obra de García Márquez, el Cronotopo del traspaso del umbral de la puerta, es un rito expectante de derivaciones de seguridad, de la misma forma que aparece en el imaginario colectivo del habitante del Caribe y de otras latitudes en general, "Deseaba de todo corazón que la puerta estuviera atrancada, y no simplemente ajustada, como ella le había prometido. Pero estaba abierta" (García, 2007, p. 13). También, es posible visualizar en esta obra literaria la puerta como la apertura al mundo, una exterioridad que nos permite tener evidencia de lo que desconocido que subyace en el universo del otro asociado a la imagen estética y vivencial de la calle. "Le dio un beso convencional, como si no hubiera estado ausente más de una hora, y le dijo: -Asómate a la puerta. / José Arcadio Buendía tardó mucho tiempo

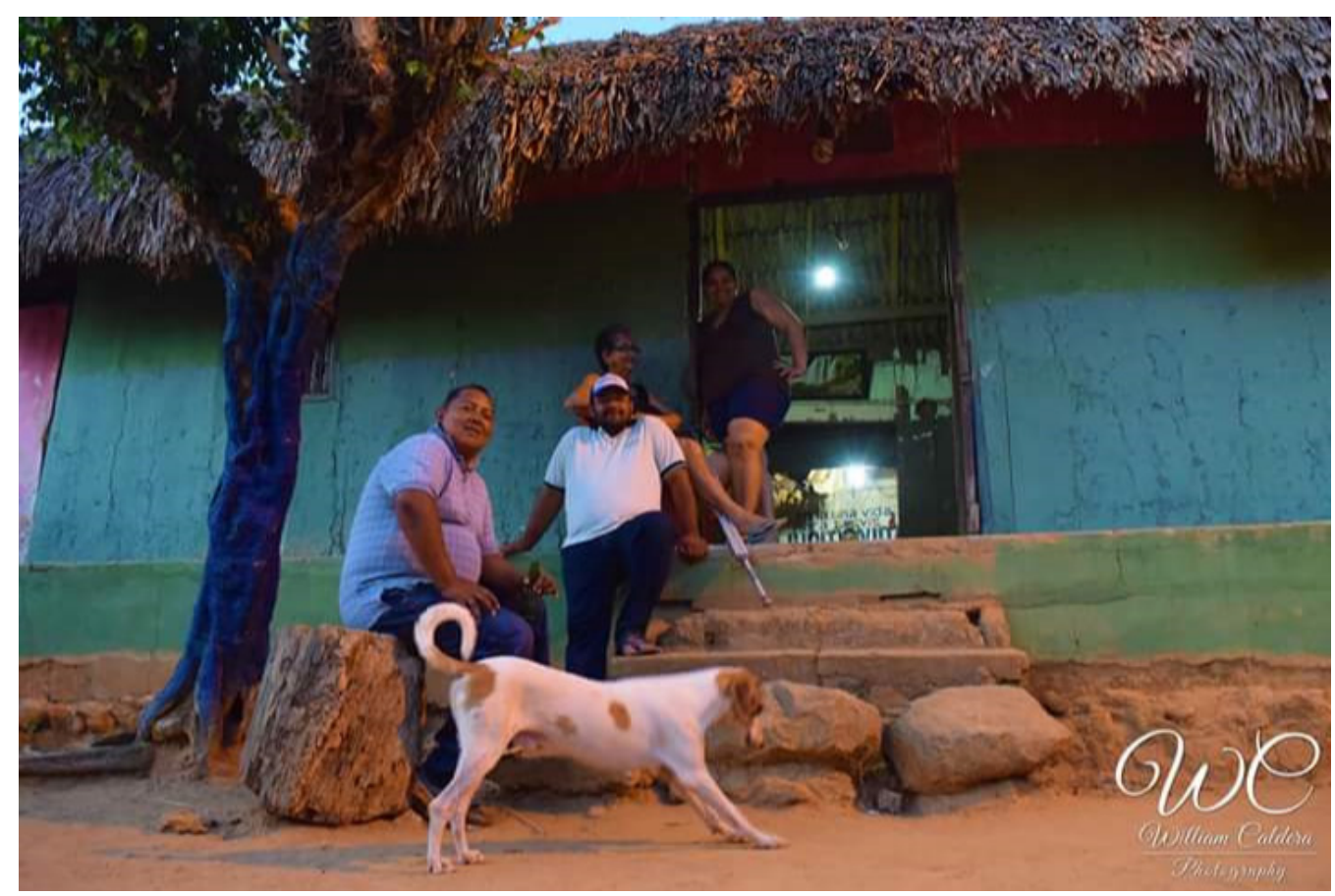

Figura 2. Personajes caribeños sentados en el umbral de acceso a la casa. Vista desde el exterior al interior de la casa. Fuente: Fotografía de William Caldera Pantoja. 
para restablecerse de la perplejidad cuando salió a la calle y vio la muchedumbre." (García, 2007, p. 15).

En el Caribe, es común encontrar en la Casa tradicional, la existencia de numerosas puertas que se disponen sobre la fachada principal y una pequeña, dispuesta lateralmente, que comunica el exterior de la calle con el patio, como si ambos espacios fueran la evidencia de lo público, tanto adentro como afuera de la Casa, "Frente a una puerta del fondo por donde entraban y salían algunos hombres, estaba sentada y se abanicaba en silencio la matrona del mecedor" (García, 2007, p. 27). Estas puertas fundan, generalmente, espacios de habitaciones que anteriormente tenían dos funciones latentes: albergar familia dentro de la estructura familiar extensa caribeña y la otra, de servir como espacio comercial donde se propician los intercambios económicos de la cosecha o cualquier otra actividad de subsistencia. Este hecho queda retratado en el texto de García Márquez (2007), de Cien años de soledad, donde se relata la travesía de Don Apolinar Moscote, el corregidor:

(...) al día siguiente alquiló un cuartito con puerta hacia la calle, a dos cuadras de la casa de los Buendía. Puso una mesa y una silla que le compró a Jacob, clavó en la pared un escudo de la república que había traído consigo, y pintó en la puerta el letrero: Corregidor (García, 2007, p. 38).

\section{LA COCINA}

La cocina en el Caribe representa el corazón del hogar. Es el lugar en donde se fabrican los elementos de gusto que dan unidad a la familia caribeña: la comida. De la misma manera como son los sabores del Caribe, vibrantes y exuberantes, así mismo es el ritual de prepararlos, acto que se hace posible en la cocina y que denota el mayor acto de afecto del hombre, alimentar, asunto que queda sugerido en el texto de García Márquez (2007): "Dispuso ensanchar la cocina para construir dos hornos, destruir el viejo granero donde Pilar Ternera le leyó el porvenir a José Arcadio, y construir otro dos veces más grande para que nunca faltaran los alimentos en la casa ( $p .37$ ).

Michel de Certeau (1999), categoriza a la cocina como el espacio que evoca las temporalidades de pasado y presente familiar, pues en ella siempre se desarrollan eventos que suscitan al recuerdo a través de sus prácticas, que, por el trascurrir del tiempo, han evolucionado sin perder la añoranza de la presentación original. De esta misma forma, se ubica como un espacio meramente familiar convergente, cuya existencia gira en torno a sus usos y no necesariamente a sus formas, "en el centro de estos sueños, está a menudo la cocina, esta 'pieza ardiente' donde la familia se reúne, teatro de operaciones de las 'artes de hacer' y del más necesario de todos ellos, el arte de alimentarse" (De Certeau, Giard, y Mayol, 1999, p. 150).

La cocina, desde muchas perspectivas, representa un lugar marcado por el género, atribuido particularmente a la mujer como individuo siempre presente en la cotidianidad de la Casa; según De Certeau (1999), en la dialéctica de la división sexual de roles familiares, los hombres aparecen excluidos de las instalaciones de la cocina, en una especie de negación al importante papel de la alimentación perpetrado desde siempre por la mujer, como motor de esta pieza material; es indispensable al momento de promulgar que la cocina es como la matriz, pues en ella se gestan las batallas de la cotidianidad de la Casa.

Las conductas alimentarias constituyen un dominio donde la tradición y la innovación importan de igual modo, donde el presente y el pasado se mezclan para atender la necesidad del momento, proporcionar la alegría del instante, adecuarse a la circunstancia. Con su alto grado de ritualización y su poderosa inversión afectiva, las actividades culinarias son para muchas mujeres de todas las edades un lugar de felicidad, placer e inversión. (De Certeau, Giard, y Mayol, 1999).

El Cronotopo de la cocina esta dado en la Casa caribeña como un espacio doméstico de permanencia que porsu constante uso ha denotando una carga simbólica en las particularidades de los rituales que en este habitáculo se suscitan. En la cocina ocurre el milagro del compartir, pues esto es lo que hace solidario al hombre caribeño, la capacidad de compartir el alimento, recurso que se ha conseguido después de intensas jornadas de trabajo. Esta conjugación de espacialidad y conformación de un sistema de valores humanos del habitante caribeño, se hace imprescindible cuando existe un dispositivo activador de la acción; en este caso, la cocina, por su representación 
psicogeográfica impulsa los valores de la caribeñidad: la solidaridad, el apoyo mutuo, la generosidad, entre otros.

El espacio de la cocina es un espacio amplio en la gran mayoría de las Casas del Caribe, ya que se incluye en ella el espacio para comer. En las viviendas vernáculas, la cocina es una habitación apartada del resto de la Casa y dispone de un espacio cubierto, sin cerramiento, en donde se ubican distintos mobiliarios que brindan comodidad en la acción de cocinar y comer, pues, generalmente, no se cuenta con una mesa formal de comedor. Este espacio contiguo representa un espacio de reunión y concentra a familiares, vecinos y amigos en cualquier hora del día, mientras que la madre controla desde el interior de la cocina todas las conversaciones y decisiones que afuera se producen.

En el Cronotopo literario, la cocina es un relato, en ella se concentran los recuerdos; por tanto, las imágenes solo pueden ser narradas y trazan memorias del adentro y del afuera de la Casa. De esta manera, la cocina representa un gran espacio de gestación de las cotidianidades y de las fantasías. La cocina es como la plaza del barrio, el lugar de la socialización y el encuentro, donde permanece la sabiduría de la madre que mientras prepara el alimento, contesta preguntas, resuelve acertijos, se entera de chismes y luego los cuenta, se da el tránsito de los vecinos de mayor confianza, es el punto de vigilancia y control de los hijos y el recuento de los pequeños acontecimientos familiares.

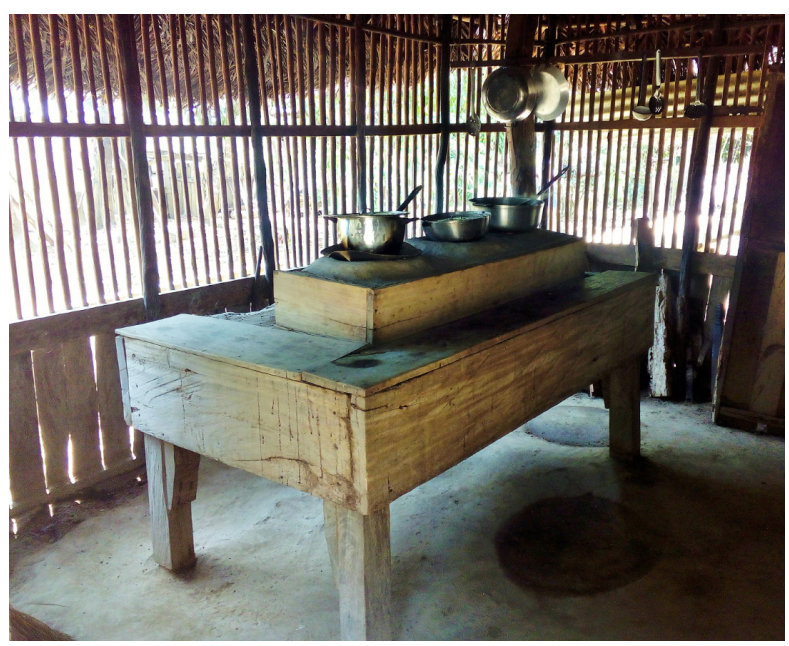

Figura 3. Cocina caribeña en casa vernácula y tradicional. Hornilla de leña construida en madera y binde.

Fuente: la autora.

\section{LA CALLE}

Si bien la calle es estudiada, desde el punto de vista urbano, como parte de la infraestructura de servicios que ofrece la ciudad, y que se dispone mediante la planificación de rutas para garantizar la conectividad de los espacios mediante acciones de movilidad. Tal como lo describe García Márquez (2007), en Cien años de soledad, en donde, José Arcadio Buendía "(...) volvió a ser el hombre emprendedor de los primeros tiempos que decidía el trazado de las calles y la posición de las nuevas casas, de manera que nadie disfrutara de privilegios que no tuvieran todos" (p. 18).

Para el habitante caribeño, la calle se convierte en una imagen cronotópica de la Casa, en tanto que en ella se posibilita la extensión de las actividades domésticas y permite, sin mayor reparo, la apropiación de este espacio como un elemento dinamizador de la familia extendida (vecinos, amigos y transeúntes).

Por un lado, la habitación del barrio a través de prácticas familiares remite a "la estructura aglutinante de la calle" que es a su vez la estructura de hormiguero de las actividades cuyo ritmo está dado por los espacios y las relaciones (De Certeau, Giard, \& Mayol, 1999, p. 2).

La calle que está justo enfrente de la Casa, se convierte en el lugar de relaciones y de juegos de niños y jóvenes que sin perder el contacto de la mirada protectora expresan y desarrollan sus capacidades lúdicas y recreativas. Esta estructura espacial es la encargada de organizar sistemáticamente el comportamiento humano en sociedad y hace visible la configuración de códigos de cortesía que varían según la tradición cultural del habitante (De Certeau, Giard, \& Mayol, 1999).

La cultura de la calle se describe a partir de las familias, los individuos solitarios y los grupos, que traen a la memoria la unidad de acción a la que Elías Canetti (1962) se refiere cuando habla de hordas de gente que representan la "expresión universal de entusiasmo colectivo" (Salcedo, 2000). Es decir, la calle funciona no solo como punto de comunicación e interacción de la gente con la vida urbana, sino que permite tocar las formas de un estar social en su conjunto, la calle otorga identidad, genera sociedad (Salcedo, 2000). Vanegas Athías, expresa en el poema Las calles de su libro Lugares comunes, lo siguiente: 
En las calles que decides transitar encuentras por fin la caída que presentías, la desolación del rechazo, el vencimiento que recibes sin lamentos, la derrota inmerecida... En las calles que adhirieron a tu piel como ese amor que nunca volverá, hallas también el coraje para seguir caminando o para morir, sin saber si sobrevendrá alguna plenitud o la nada (Vanegas, 2006, p. 2).

La calle se cierra ante eventos festivos familiares (cumpleaños, bodas, funerales, entre otros), ante reuniones comunales y juegos barriales de futbol, escondite y rayuela. La calle se organiza conjuntamente en épocas de integración barrial como semana santa, navidad y año nuevo $y$, se permite el intercambio y la apropiación de la misma sin la preocupación permanente de la acción cotidiana del tránsito. Xavier Monteys (2013) indica que no es necesario establecer una ubicación limítrofe entre la calle y la Casa, sino que hay que dejar que los usos de un lugar y otro fluyan con naturalidad, "la Casa va a la calle como la calle a la Casa" (p. 133).

\section{DISCUSIÓN}

Identificar las trazas de una identidad cultural, presente en el ámbito habitacional del Caribe colombiano, es posible mediante la dialógica intertextualidad que existe entre este objeto socio-espacial representado en la Casa caribeña, con las instancias de memoria colectiva que se hacen evidentes a través de la Literatura. La representación del universo vital humano se corresponde a la representación del universo narrativo que proporciona un mapa semántico de imagen cronotópicas, que aprovecha la realidad cultural y espacial como punto de partida de la expresión artística literaria (Valdelamar, 2008).

El Cronotopo estudiado desde la perspectiva del hábitat (habitáculo y habitante) nos brinda una herramienta hermenéutica como converger en un mismo foco la poética y la retórica de la Arquitectura, que según Muntañola (2010) se expresan en un tiempo mental (mente y cultura), un tiempo histórico (prácticas sociales) y un tiempo físico (territorio) con el que nace el proyecto arquitectónico, lo que

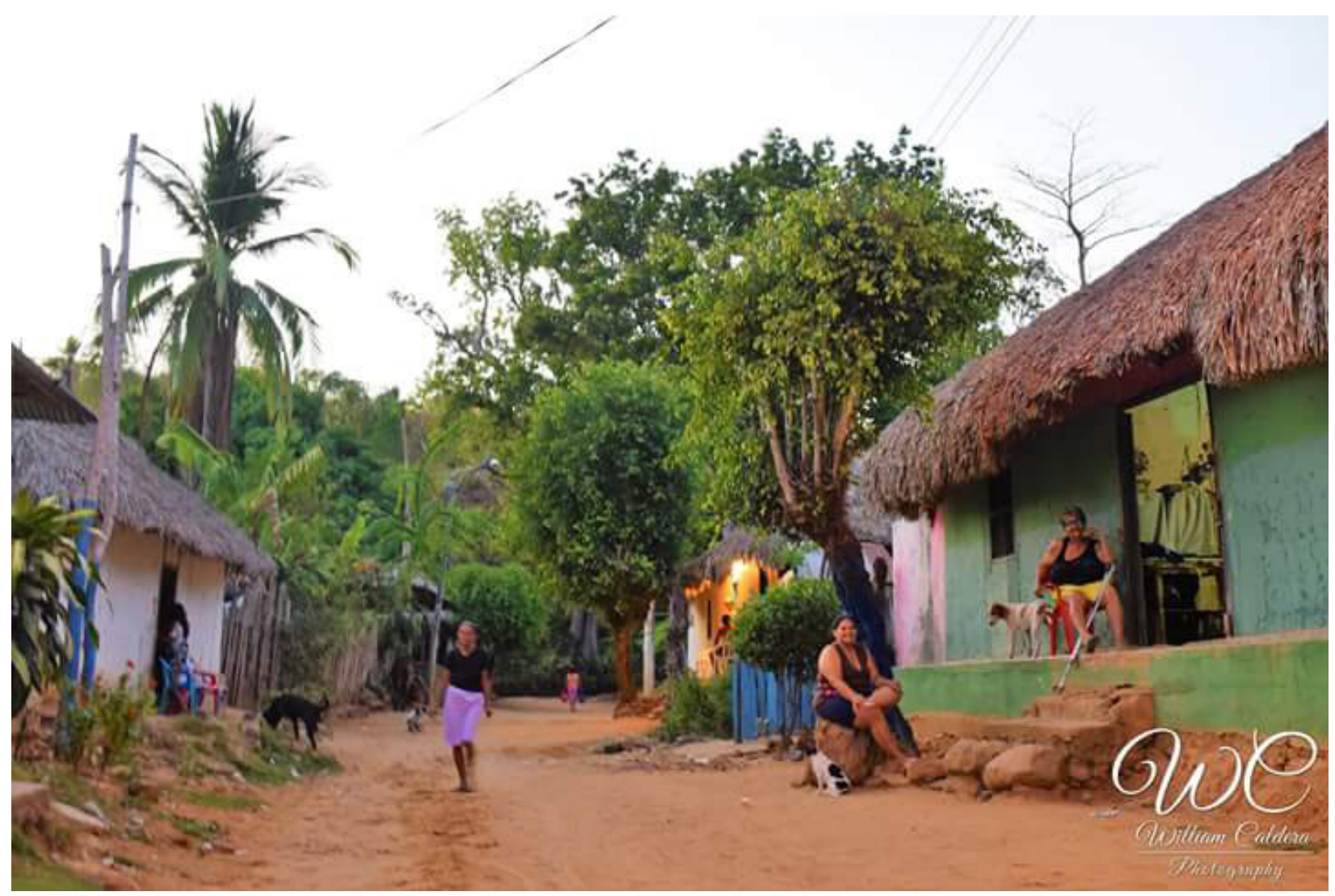

Figura 4. Dinámica de una calle caribeña y su unidad público-privada. Fuente: Fotografía de William Caldera Pantoja. 
indica que las configuraciones de la Casa caribeña son producto de las derivaciones socio-culturales y geo-históricas en las que esta imbuido el existir y el habitar humano en esta porción del territorio.

Los proyectos actuales de Arquitectura se estructuran básicamente como redes cronotópicas que, en el caso del Caribe, guardan un sincretismo cultural que reproduce estilos de vidas y modos de habitar con una fuerte carga simbólica que mantiene la pregnancia de los lugares en los espacios íntimos de la memoria, como resultado de la activación psicológica y emotiva que producen los lugares y las prácticas del habitar que en ellos se desarrollan. De ahí, que, como afirma De Certeau, et al (1999) "Nuestras viviendas sucesivas jamás desaparecen del todo, las dejamos sin dejarlas, pues habitan a su vez, invisibles y presentes, en nuestras memorias y en nuestros sueños. Viajan con nosotros" (p. 150).

Paul Ricoeur (2002), en su texto "Arquitectura y Narrativas", expone el carácter integrativo que debe existir entre la Arquitectura y la Literatura, la Arquitectura narrada y la palabra dibujada, esto, le permitió considerara que:

Una obra arquitectónica es, por consiguiente, un mensaje polifónico ofrecido a una lectura a la vez englobante y analítica. El proyecto es para la obra arquitectónica una especie de «puestaen-intriga» que, como se ha visto, no recoge únicamente acontecimientos, sino también puntos de vista, a modo de causas, motivos y factores del azar. La «puesta-en-intriga» se encaminaba así hacia su transposición, del tiempo al espacio, mediante la producción de una casi-simultaneidad de sus componentes, la reciprocidad entre el todo y la parte, y la circularidad hermenéutica de la interpretación, que resultaba ser su correspondiente exacto en las implicaciones mutuas de los componentes de la Arquitectura (p. 21).

La Arquitectura y la Literatura del Caribe colombiano se constituyen en el signo de la subjetividad cronotópica derivada de la acción humana; son una huella legible del tiempo físico y el tiempo social en el que se desarrolla el habitar cotidiano, entendiendo la relación afectiva y significativa existente entre el individuo y el espacio. Es por esto que la narrativa caribeña tiene un alto manejo descriptivo, con el fin de recrear la imagen física del espacio narrado, como unidad principal en donde se desarrolla la acción del personaje. El uso de una prosa lírica, representa la exploración plástica del intimismo como parte del diseño psicológico del personaje, pues las connotaciones significativas que representan los Cronotopos espaciales hacen evidentes los recursos pertenencia y afectividad hacia los mismos.

Esta pertenencia y sentido de apropiación de los espacios es lo que Vidal y Pol (2005) categorizan como construcción del espacio simbólico o conformación de lugares en el que se profundizan los vínculos que establecen las personas, con las características físicas y estructurales del espacio en relación a las prácticas sociales que en estos se desarrollan y a las interacciones simbólicas entre los sujetos de la escena. Lo que nos permite pensar que los eventos generados dentro de la dinámica cotidiana de habitar la Casa, cargados de una alta expresividad, característica fundamental de los rasgos psicosociales de identidad del habitante caribeño, son fundamentales en el proceso de apropiación de los espacios.

Esto quiere decir que las formas en los que se apropian los lugares están mediadas por una fuerte identidad cultural que particulariza y expresa la forma de ser y el hacer visible, en el dispositivo arquitectónico, público o privado, con los que se construye el territorio, lo que nos permite hablar de una identidad cultural habitacional para el Caribe colombiano.

\section{CONCLUSIONES}

De todo esto es posible concluir que:

La Arquitectura se verbaliza, en tanto que, al mencionar un espacio, la actividad que allí se realiza es narrada y expandida, a través de formas que se yuxtaponen y entrelazan. Esto permite una comprensión de la relación entre Arquitectura y Literatura como signos de la expresividad humana; la exteriorización del universo vital que subyace en la memoria colectiva, consciente 0 inconscientemente. Así, el espacio arquitectónico no aparece como algo neutro, sino como la corporeización de imágenes que pertenecen profundamente a una determinada cultura; imágenes que van modelándose y cambiándose, a medida que ocurren ciertos hechos históricos. 
El contraste de lo aparentemente superficial y lo profundo de un objeto arquitectónico, que como la Casa, es capaz de constituirse en un lenguaje memorial, recogido en su silencio, pero que expresa la evolución de sus hablas y escrituras, de sus marcas y de sus representaciones que perduran como el testimonio de una sociedad que habla con las cosas, que hace de los objetos su forma de expresión y su manera más material de incorporar y significar el mundo. En ella, en la Casa, se sintetizan múltiples relaciones afectivas, dimensiones y experiencias corpóreas, anudadas a un sentimiento de colectividad y de individualidad, en suma, a una visión de sociedad y de cultura.

Para entender la poética del Caribe, vista desde la Casa, es necesario captar la fuerza del imaginario en el espacio-tiempo regional, como lo son el canto de los pájaros en los aleros de los techos y los techos mismos ordenando el murmullo de la acústica de los lugares; es, por esto, que un lugar es un punto de equilibrio poético y un ordenador de las cosas vivientes, no de las cosas cosificadas, $\sin$ vida, puestas como simple ornamento.

Las trazas de una identidad cultural habitacional en el Caribe, al igual que el desarrollo de estas mismas identidades en otras latitudes, adquieren fuerza como elementos particularizantes de la experiencia globalizadora en la que esta imbuido el contexto arquitectónico inmobiliario. Esta memoria de identidad permite lograr, así sea en poco, una caracterización espacial propia de las nociones de la Cultura y el Territorio, como derecho a una Arquitectura con sentido del lugar, que si bien no se limita o restringe a las tendencias globalizantes, si defiende y apropia las espacialidad y las prácticas de los Cronotopos que los diferencian, en este afán de homogenizar el mundo.

\section{REFERENCIAS}

Bajtín, M. (1989). Teoría y estética de la novela. Madrid: Taurus.

Bustos, R. (1999). El Caribe purgatorial: Héctor Rojas Herázo o la imaginación del fuego. En I. I. Caribe, IV Seminario Internacional de Estudios del Caribe: Memorias (págs. 39 - 50)). Barranquilla: Instituto Internacional de Estudios del Caribe.

Camargo, J. (1994). ;Caribe soy! Raíces musicales afroantillanas. Medellín: Edit. Salsa y cultura.

De Certeau, M., Giard, L., \& Mayol, P. (1999). La invención de lo cotidiano II - Habitar, cocinar. México: Universidad Iberoamericana.

Díaz, M. (2014). Región Caribe de Colombia. Cali: Edit. IM Editores.

Ellard, C. (2016). Psicogeografías: la influencia de los lugares en la mente y el corazón. Barcelona: Planeta.

Ferrer, R. (2002). El Caribe en la obra de Raúl Gómez Jattin. Estudios de Literatura Colombiana. 10:109-114.

García, G. (2007). Cien años de soledad. Madrid: Alfaguara.

Gómez, R. (1995). Poesía 1980-1989. Bogotá: Norma.

Gutiérrez, V. (1996). Familia y cultura en Colombia (Cuarta ed.). Medellín: Universidad de Antioquia.

Martínez, N. (2013). El patio de la casa como territorio estético y su relación con el espacio artístico. Arte \& Diseño, 56 - 60. 
Moreno, V. (2020). El patio y el pueblo. México D.F. Universidad Autónoma de México..

Muntañola, J., y Muntañola, D. (2010). La sociología del espacio al encuentro de una Arquitectura oculta en la educación. RASE, 4(2), 133-151.

Nieves, J. (1999). Dinámicas de campo en el Caribe colombiano. En I. I. Caribe, IV Seminario Internacional de Estudios del Caribe: Memorias (págs. 21 - 28). Barranquilla: Universidad del Atlántico.

Ricoeur, P. (2002). Arquitectura y Narrativa. Arquitectonics, 9-30.

Ricoeur, P., y Muntañola, J. (2002). Arquitectura y hermenéutica: Diálogo entre Paul Ricoeur y Josep Muntañola. Arquitectonics. 4:47-52.

Rojas, H. (1986). Celia se pudre. Madrid: Alfaguara.

Rojas, H. (2006). Yo soy del patio de mi casa. En M. C. Torres, identidad Caribe. Síntesis y génesis de la nacionalidad colombiana. Bogotá: Géminis.

Salcedo, M. T. (2000). Escritura y territorialidad en la cultura de la calle. En R. Uribe, Antropologías transeúntes (págs. 157-194). Bogotá: Instituto Colombiano de Antropología e Historia.

Saldarriaga, A. (2019). ¿Cómo se habita el hábitat? Los modos de habitar. Procesos Urbanos. 6:22-33.

Valdelamar, L. (2008). El Cronotopo del patio en textos de cuatro autores del Caribe colombiano. Visitas al patio. 1:45-70.

Vanegas, B. (2006). Los Lugares comunes. Bucaramanga: SYC Editores.

Vidal, T., y Pol, E. (2005). La apropiación del espacio: una propuesta teórica para compender la vinculación entre las personas y los lugares. Anuario de Psicología. 36(3):281-297.

Zapata, M. (2006). La identidad costeña, síntesis y génesis. En M. C. Torres, Identidad Caribe. Síntesis y génesis de la nacionalidad colombiana. Bogotá: Géminis. 